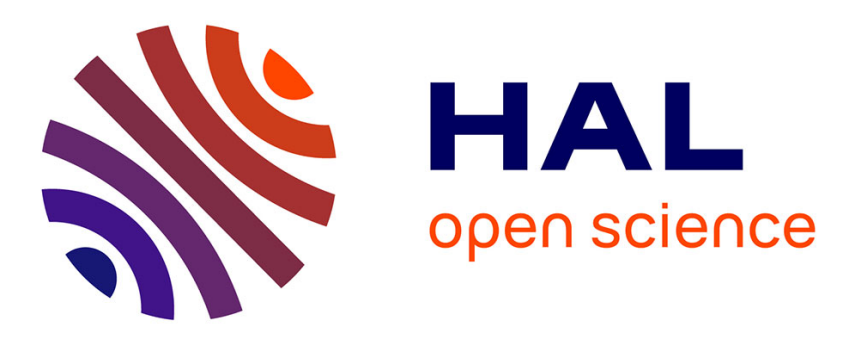

\title{
Geophysical and geochemical models of mantle convection: Successes and future challenges.
}

\author{
Yanick Ricard, Nicolas Coltice
}

\section{To cite this version:}

Yanick Ricard, Nicolas Coltice. Geophysical and geochemical models of mantle convection: Successes and future challenges.. Robert Stephen, John Sparks, Christopher Johns Hawkesworth. The State of the Planet: Frontiers and Challenges in Geophysics, American Geographical Union (AGU), pp.59-68, 2004, Geophysical Monograph Series, volume 150. AGU Code GM1504157., 0-87590-415-7. ensl00103931

\section{HAL Id: ensl-00103931 \\ https://hal-ens-lyon.archives-ouvertes.fr/ensl-00103931}

Submitted on 5 Oct 2006

HAL is a multi-disciplinary open access archive for the deposit and dissemination of scientific research documents, whether they are published or not. The documents may come from teaching and research institutions in France or abroad, or from public or private research centers.
L'archive ouverte pluridisciplinaire HAL, est destinée au dépôt et à la diffusion de documents scientifiques de niveau recherche, publiés ou non, émanant des établissements d'enseignement et de recherche français ou étrangers, des laboratoires publics ou privés. 


\title{
Geophysical and geochemical models of mantle convection: successes and future challenges
}

\author{
Yanick Ricard and Nicolas Coltice \\ Laboratoire de Sciences de la Terre, Ecole Normale Supérieure de Lyon, Lyon, France
}

\begin{abstract}
Although more and more robust evidence for whole mantle convection comes from seismic tomography and geoid modeling, the rare gases and other isotopic or trace element signatures of ridge and hotspot basalts indicate the presence of various isolated geochemical reservoirs in the mantle. We discuss this discrepancy between fluid dynamic views of mantle convection and chemical observations. We compare the standard model of geodynamicists where the mantle behaves as a fluid mostly heated from within with the findings of seismic tomography. We suggest that a significant part of the subducted oceanic crust transforms into dense eclogitic assemblages, and partially segregates to form a layer that has grown with time above the Core Mantle Boundary (CMB) and should correspond to the D" layer of seismological models ( $280 \mathrm{~km}$ thick). We show how a two component marble cake mantle filling the whole mantle except D" can account for the variability of Ocean Island Basalts (OIB) and Mid-Ocean Ridge Basalts (MORB) in rare gases. We then present the state of the art in thermochemical convection of the mantle and emphasize the numerical and conceptual progress that must be made to provide a quantitative test of the geochemical hypotheses.
\end{abstract}

\section{Introduction}

Geochemists, seismologists and geodynamicists try to understand the behavior of our planet by means of very different tools. The observations of geochemists provide a time integrated view. The isotopic, trace or major element concentrations and ratios that they measure are the results of 4.5 byrs of dynamics that includes major events like core segregation and the formation of the continental crust. Seismologists, on the other hand have only access to a snapshot of this evolution, namely the present-day structure of the Earth.

There are no obvious reasons to believe that the timeintegrated and the instantaneous views of the Earth should be identical. Using experimentally measured parameters (like densities, viscosities) and physical laws (mass, energy and momentum conservation), geodynamicists have the difficult task of proposing a scenario that is consistent with these two viewpoints. We are far from a detailed understanding of how the mantle works, but at least we can describe where the problems are and suggest some possible solutions.

\section{The mantle seen by geophysicists}

The striking advances in mantle tomography in the last 20 years have made it difficult to believe that mantle flow can be stratified at any depth by any sharp discontinuity. Since the first global images 20 years ago, inversion methods have been improved by more precise location of the events, local grid refinements (Bijwaard et al., 1998), multibounce phase modeling (Grand et al., 1997), a more accurate description of wave propagation (Montelli et al., 2003), etc. Although there are still significant differences between the results, all models share sheet-like fast structures reminiscent of past subduction. These structures are very well defined under North and Central America (through most of the mantle) and below the Tethyan suture from the Mediterranean sea to the north of Australia (at least down to mid mantle).

These tomographic observations rule out a strict stratification of the mantle. This of course does not mean that slabs penetrate the lower mantle without difficulty, nor that all slabs reach the core-mantle boundary. In various places, like around the Philippine plate or Tonga, folded slabs or slabs flattening in the transition zone are observed (Fukao et al., 2001). In other places the sheet structure of the fossil slabs seems to fade away around mid-mantle depths or are replaced by finger-like downwellings. These two observations are in good agreement with geodynamic models.

The oceanic lithosphere cools over a thickness $L$ during its thermal contraction in spreading at the sea floor. The thermal diffusion equation implies the well known relation

$$
L^{2} \sim 4 D_{t h} t
$$

where $D_{t h}$ is the thermal diffusivity and $t$ the age of the lithosphere. The same diffusion equation implies that this 
lithosphere reheats after a time of order $t / 4$ in the deep mantle (the lithosphere is cooled only from its top but is reheated from both sides). This means that the lithosphere lasts around 30-40 myrs in the mantle before halving its temperature deficit. With a sinking velocity of $2 \mathrm{~cm} / \mathrm{yr}$ in the lower mantle, this lithosphere can travel down to the mid lower mantle before being sufficiently reheated to loose its integrity. This indeed corresponds to the depth where many slabs observed by tomography in the shallower mantle seem to fade out. This simple calculation agrees with more realistic numerical simulations (Bunge et al., 1998).

The likely viscosity increase through the transition zone causes a decrease in the sinking velocity of the subducting material and in the dip angle of the descending slabs, similar to a refraction kink. The effects of phase changes from ringwoodite to perovskite plus oxides, that occur at a greater depth in the cold slabs than in the surrounding mantle, also tend to affect the slab penetration in the lower mantle. When these effects are taken into account in addition to potential trench migrations (roll-back), numerical simulations are able to reproduce in a very realistic way all the complexities of mid mantle slab trajectories, but the conclusion is that viscosity increases, phase transitions and roll back do not impede a large scale flow throughout the mantle (Christensen, 1996). A comparison between tomographic images and paleogeographic plate reconstructions shows a close agreement between the fast structures and the positions of Cenozoic and Mesozoic trenches at global (Ricard et al., 1993) and regional scales (Van der Voo et al., 1999).

Subduction removes primitive and radiogenic heat by burying cold lithosphere at great depths. There are various indications that this is the major source of buoyancy that drives the mantle (Bercovici et al., 2000). The return flow associated with these active downwellings is mostly passive and should consist of a uniform upwelling flow with an averaged velocity at least one order of magnitude lower than the slab sinking velocities (in the proportion of the surface area of the descending slabs to the surface area of the Earth). As a simple numerical example, the downgoing velocities should be of the order of $10 \mathrm{~cm} / \mathrm{yr}$ in the upper mantle, and a few $\mathrm{cm} / \mathrm{yr}$ in the lower mantle where viscosity increases by one or two orders of magnitude. Except for the velocities of actively rising material in plumes, the background upwelling velocities should be around a few $\mathrm{mm} / \mathrm{yr}$. This behavior is very different from what occurs with a bottom heated fluid where upwellings and downwellings have similar absolute velocities. The flow regime is such that a complete overturn in the internally heated mantle (transport from ridge to trench, subduction through the whole mantle, and back to the ridge) is controlled by the return flow, is thus very slow and the time scale is of the order of 1 byr. This simple scenario indicates that isotopic ratios involving radioactive chains like $\mathrm{U}-\mathrm{Pb}$ and $\mathrm{Rb}-\mathrm{Sr}$ have enough time to evolve and generate observable heterogeneities.

The role of plumes in convection models is to carry the excess heat out of a hot boundary layer. No experimental or numerical model has ever generated plumes from within of a convection cell. An obvious candidate for the source of hotspots is the core-mantle boundary where heat diffuses out from the core throught a thermal boundary. The existence of other thermal boundary layers in the mantle, at 670 $\mathrm{km}$ depth or more speculatively on top of an abyssal layer, has no clear observational support (Castle and van der Hilst, 2003). The plumes themselves are very difficult to observe although striking progress has been made in recent years (Nataf and VanDecar, 1993; Montelli et al., 2003). This difficulty comes from their expected very small dimensions and low excess temperature. According to geodynamicists, hotspots carry buoyancy fluxes from $7000 \mathrm{~kg} \mathrm{~s}^{-1}$ for Hawaii to $300 \mathrm{~kg} \mathrm{~s}^{-1}$ for the smaller detectable ones (Davies, 1988). Their excess temperature is only 250 K (Sleep, 1990) and their ascent velocity should be significantly larger than a typical plate velocity to resist entrainment by the large scale mantle flow (Steinberger and O'Connell, 1998). These figures imply radii of the order of $10 \mathrm{~km}$ up to $100 \mathrm{~km}$ for the strongest plumes, indeed very small to be detected with present techniques.

This agreement between simple thermal internally heated convection and seismic observations is only first order. Seismologists have observed various structures in the deep mantle that probably have chemical origins. In D" near the coremantle boundary (CMB), diffractive bodies (Weber, 1996), anisotropy (Vinnik et al., 1995), and ultra-low velocity zones (Garnero and Helmberger, 1995), suggest complex small scale thermochemical processes. At a larger scale, subtle contradictions between $\mathrm{P}$ - and S-wave models (for example, anti-correlations of the anomalies and changes in $\mathrm{Vp} / \mathrm{Vs}$ ratios) also point to chemical variations in the deep mantle (Saltzer et al., 2001). Increased complexity in the models is necessary for seismologists as well as for dynamicists. The density variations in the mantle are not only due to thermal expansion but are also related to mineralogical and chemical variations.

\section{Geochemical observations}

The differentiation of the mantle through melting, alteration and other processes has significantly transformed the initial distribution of chemical elements. For this reason, the geochemistry of mantle derived rocks contributes to constraining models of mantle dynamics.

The initial bulk chemical composition of the Earth in refractory elements is modeled using the chemistry of meteorites and especially carbonaceous chondrites, the supposed parent bodies of our planet (McDonough and Sun, 1995). The initial composition in volatile elements is still questioned since significant volatilization probably occurred during Earth's accretion (Tyburczy et al., 1986). During Earth's differentiation, some chemical elements are retained in the silicated mantle and crust (the lithophile elements), others form iron alloys in the core (the siderophile elements). For refractory lithophile elements and isotopes, the difference 
between the present-day chemistry of the mantle and the initial composition reflects the history of mantle evolution and mixing.

The simplest model of present-day distribution of lithophile elements is to suppose that the primitive mantle evolved through extraction of the crust leaving a residual mantle. As a consequence, the chemistry of the continental crust should be complementary to the present-day mantle relative to its primitive composition. A simple test can be performed with uranium (which is also valid for most other elements): the continental crust contains at most $3.910^{16} \mathrm{~kg}$ of uranium (Rudnick and Fountain, 1995) and the whole mantle would contain $3.210^{16} \mathrm{~kg}$ (Jochum et al., 1983) assuming that its composition is similar to that of the shallow mantle. This would make a total of $7.110^{16} \mathrm{~kg}$ of uranium for the silicate Earth. However, the primitive mantle should contain $8.410^{16} \mathrm{~kg}$ of uranium (McDonough and Sun, 1995). At least $15 \%$ of the uranium is therefore missing in the balance. One could store the missing uranium in the outer core, which then would have a uranium concentration similar to that of the shallow mantle of $8 \mathrm{ppb}$. This seems highly improbable as uranium is not a siderophile element. The other solution is to invoke at least one more hidden domain having a composition different from that of the shallow mantle, that unlike the shallow mantle cannot be sampled.

The composition-volume tradeoff of this reservoir can be derived from the mass balance

$$
M_{p m} C_{p m}=M_{c c} C_{c c}+M_{s m} C_{s m}+M_{h} C_{h},
$$

where $M_{i}$ and $C_{i}$ are the mass and the concentration of an element in a reservoir $i$. The reservoirs are the primitive mantle, $p m$, the continental crust, $c c$, the shallow mantle, $s m$ and a hidden reservoir $h$. We have shaded in Figure 1 the possible range of mass and composition of this reservoir for two elements, uranium ( $\mathrm{U}$ top) and aluminum (Al bottom). The possible concentrations of this U- and Al-rich hidden reservoir are of course higher than those in the shallow mantle (SM). This graph shows that a hidden reservoir the size of the lower mantle would not be primitive, since the $\mathrm{U}$ and $\mathrm{Al}$ contents differ from those of the bulk silicate Earth, BSE. A primitive reservoir would represent only 30-60\% of the mass of the lower mantle; if D" is the hidden reservoir ( $\sim 280 \mathrm{~km}$ thick on top of the core-mantle boundary), its $\mathrm{U}$ and $\mathrm{Al}$ contents would be roughly similar to that of MORBs. A reservoir with a volume and concentrations comparable to that of the continental crust, $\mathrm{CC}$, would be acceptable for the $\mathrm{U}$ budget but would not contain enough $\mathrm{Al}$.

Another source of information comes from isotopes. Two isotopes of the same element do not fractionate upon melting and so the erupted material has the same isotopic ratio as its source. However, melting, or other modification of rocks (e.g. dehydration, alteration and phase changes) can fractionate the parent-daughter ratio for radioactive isotopes. The elements that concentrate in the melt are called incompatible, those remaining in the residue are called compatible. As a consequence, a melt and a residue will have signifi-
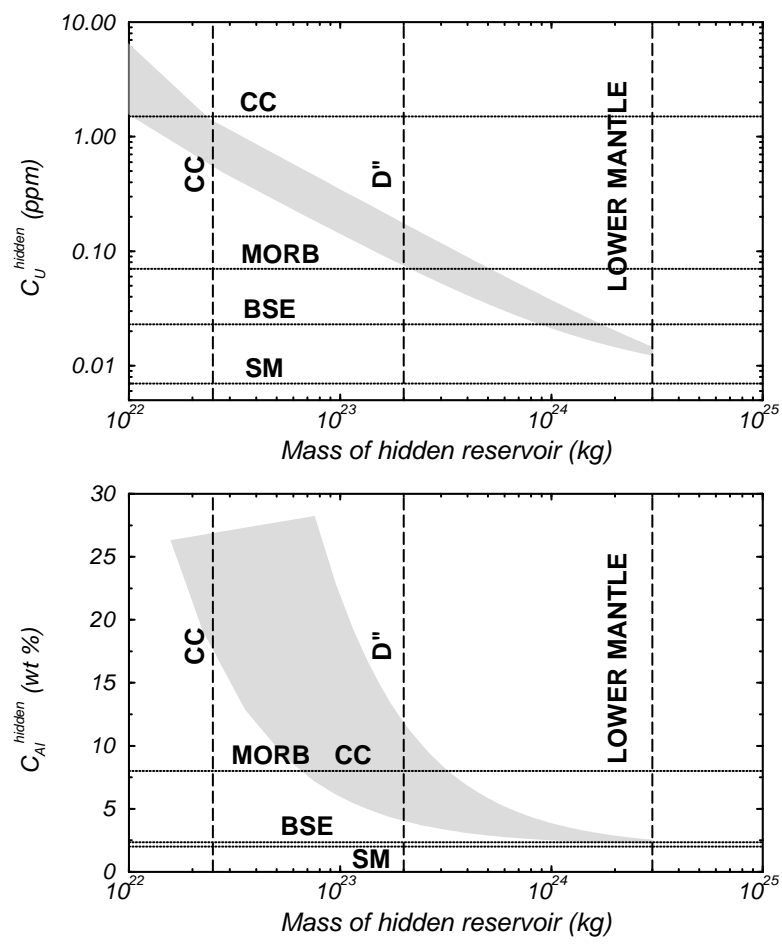

Figure 1. The possible concentrations of two lithophile incompatible elements (top uranium, bottom aluminum) in the hidden reservoir as a function of mass of this reservoir are indicated by shadowed areas. To account for the abundance of the incompatible elements in the bulk silicate Earth (BSE), the continental crust (CC) and the shallow mantle (SM) are not enough. A hidden reservoir is necessary with a lithophile incompatible concentration larger than in the shallow mantle. This reservoir could have a rather small volume (like that of D") but be very rich in incompatible elements (with concentrations somewhat similar to that of subducted MORBs). Alternatives could be a lower mantle somewhat depleted in $\mathrm{U}$ and primitive in $\mathrm{Al}$ or a thick primitive abyssal layer ( $\sim 50 \%$ of the lower mantle). 
cantly different isotope ratios after a time comparable to the radioactive decay time.

We will not discuss the whole isotope taxonomy of mantle derived rocks, but oceanic island basalts (OIBs) and mid ocean ridge basalts (MORBs) display a specific diversity (see Hofmann, 1997 for a review). At the end of the 80's, Sr, $\mathrm{Nd}, \mathrm{Pb}$ were the most studied isotope systems and a specific effort was made to define mantle poles (Zindler and Hart, 1986). DMM (depleted MORB mantle) was the most depleted MORB sample, HIMU was the sample with the highest time integrated $\mathrm{U} / \mathrm{Pb}$ ratio, $\mathrm{EM}-1$ (enriched mantle 1) was the sample with the lowest ${ }^{143} \mathrm{Nd} /{ }^{144} \mathrm{Nd}$ and EM-2 (enriched mantle 2) was the sample with the highest ${ }^{87} \mathrm{Sr} /{ }^{86} \mathrm{Sr}$. Further analytical developments in chemistry highlighted new poles for new isotope systems (Schiano et al., 1997). Such poles are concepts rather than observed samples and correspond to singular rather than common compositions.

However, these virtual poles can be associated with geological/petrological end-members. For example, the HIMU pole probably reflects the presence of ancient altered crust in the source (Hofmann and White, 1982). Various isotope systems can be used to identify the petrological components in the source of magmas like $\delta^{18} \mathrm{O}$, Os, Hf and the presence of ancient oceanic crust sections has been detected in the source of MORBs and of all OIBs (Eiler et al., 1996; Schiano et al., 1997; Blichert-Toft, 1999).

These observations show that the mantle is made of a heterogeneous mixture of rocks that have different time integrated histories of differentiation. For some samples, the time needed to develop their specific signature is of the order of 2 billion years (Hofmann, 1997). In general, the homogeneity of MORBs contrasts with the heterogeneity of OIBs, but for some isotope ratios the diversity is comparable. The fact that various hotspots are associated with volcanic chains that have crossed ridges indicates that these hotspots at least, and we think all hotspots, have a deep origin (Richards et al., 1989). The heterogeneity of OIBs should reflect the heterogeneity of the deep mantle.

Volatiles provide information on degassing, especially light noble gases that are not recycled into the mantle. The ${ }^{3} \mathrm{He} /{ }^{4} \mathrm{He}$ ratio evolves through degassing of the stable isotope ${ }^{3} \mathrm{He}$, and through radiogenic growth of ${ }^{4} \mathrm{He}$ produced by decay of $\mathrm{U}$ and $\mathrm{Th}$. The standard interpretation of higher ${ }^{3} \mathrm{He} /{ }^{4} \mathrm{He}$ ratios in some OIBs, like Hawaii or Iceland, is that their source is rich in ${ }^{3} \mathrm{He}$, hence mostly undegassed (Allégre et al., 1986). For that reason, many authors suggest that there are still some undegassed rocks within the convective mantle, and hypothesize the existence a deep primitive layer, sometimes identified with the lower mantle, which would also contain the missing incompatible elements.

Argon is a better candidate than helium to monitor the degassing of the planet since it does not escape from Earth's atmosphere, unlike helium. It is well known that about half of the argon- 40 that has been produced by potassium- 40 decay has not been degassed and cannot be found in the continental crust or the shallow mantle (Allègre et al., 1996). However, the argon budget is controlled by the potassium budget, a volatile element for which the bulk abundance is not well known. Assuming the frequently quoted K/U ratio of 12700 (Jochum et al., 1986), a primitive, undegassed lower mantle would close the budget. However, a whole mantle with shallow mantle composition similar to that of the source of MORBs overlying a potassium rich D" layer made of segregated oceanic crust, is another way to close the budget if the bulk Earth K/U ratio was $20 \%$ lower (Coltice and Ricard, 2002).

In conclusion, every isotope system can potentially provide a constraint on mantle history but the signal is not easy to interpret in terms of mantle dynamics. The major observations are (a) that MORBs and OIBs often differ in regard to their isotope signature and heterogeneity, (b) subducted rocks are recycled in the mantle and dominate within some plumes, (c) noble gases suggest that rocks with various degrees of degassing coexist within a vigorously convective flow.

\section{Physics of mixing}

The chemical heterogeneities of the mantle may have different origins. The initial chemical conditions of the mantle when plate tectonics, or some kind of convection started, is certainly poorly known. Various researchers have discussed the possible survival of primitive material in the form of a continuous deep layer (Kellogg et al., 1999) or of entrained lumps (Becker et al., 1999). The heterogeneity could also be the mere consequence of plate tectonics. The oceanic ridges associated with the divergent motion of the plates entrained by subduction induce an adiabatic melting due to pressure release. The chemical elements are partitioned between the basaltic melt and the residual. This is of course a major source of mantle heterogeneities.

Whether they are primitive or recycled, heterogeneities are then entrained by convection and mixed back in the mantle. Ultimately, complete mixing is obtained when chemical diffusion has erased the heterogeneities. However, without deformation (stirring), the chemical solid-state diffusion alone is an incredibly slow process. The diffusivity of uranium for example is of order $D_{c h} \sim 10^{-19} \mathrm{~m}^{2} \mathrm{~s}^{-1}$ (Hofmann and Hart, 1978). Since the formation of the Earth (4.5 byrs), uranium would only have migrated by $20 \mathrm{~cm}$. Even noble gases that are many orders of magnitude more mobile than uranium, $D_{c h} \sim 10^{-13} \mathrm{~m}^{2} \mathrm{~s}^{-1}$ (Trull and Kurtz, 1993), would only have migrated by $200 \mathrm{~m}$. Without stirring, elements are basically frozen in the mantle.

However, the mantle is not steady and convection stirs, stretches and folds the heterogeneities until they reach small enough dimensions, where diffusion can be efficient. To provide a quantitative understanding of the interaction between deformation and diffusion, we can consider a heterogeneity localized in an infinite stripe of thickness $a(t)$ and assume that the concentration only varies in the $y$ direction, perpen- 
dicular to the stripe. Instead of writing the diffusion equation in an Eulerian fixed frame as usual, we can write the elemental balance across the deforming stripe itself; using the Lagrangian variable $\tilde{y}=y / a(t)$, one can demonstrate that diffusion produces

$$
\frac{d C}{d t}=D_{c h}\left(\frac{a_{0}}{a(t)}\right)^{2} \frac{d^{2} C}{d \tilde{y}^{2}} .
$$

Stretching therefore increases the apparent diffusivity by a factor $\left(a_{0} / a(t)\right)^{2}$. By analogy with the usual diffusion solution, one can guess that a stripe of initial thickness $a_{0}$ is erased by diffusion after a homogeneisation time $t_{h}$, so that

$$
a_{0}^{2} \sim 4 D_{c h} \int_{0}^{t_{h}}\left(\frac{a_{0}}{a(u)}\right)^{2} d u .
$$

Although we have not performed a rigorous demonstration of the two previous equations, the result agrees with more sophisticated approaches (e.g. Kellogg and Turcotte, 1986; Olson et al., 1984).

To perform some quantitative estimates, we can consider a heterogeneity in a strongly time dependent flow. In this case the distance between two points grows exponentially with time (Ottino, 1989) and as in a pure shear deformation, one has

$$
a(t)=a_{0} \exp (-A t)
$$

The parameter $A$ has the dimension of a strain rate; it is, however, an effective strain rate computed along the Lagrangian trajectories of the flow and it is not equivalent to the instantaneous strain rate $\dot{\epsilon}$ of the flow. The quantity $A$ is also called a finite-time Lyapunov exponent and even for very simple flows, its relationship with the average strain rate is far from being obvious (Ferrachat and Ricard, 1998). In general it also depends on the rheological properties of the heterogeneity with respect to its surroundings (du Vignaux and Fleitout, 2001). Combining (3) and (5) indicates that in time dependent flows, the apparent diffusivity depends on the Lyapunov exponent $A$ and varies exponentially with time like $D_{c h} \exp (2 A t)$. Equation (4) implies

$$
t_{h} \sim \frac{1}{2 A} \log \frac{A a_{0}^{2}}{D_{c h}} .
$$

Numerical application considering the fate of an anomaly related to former oceanic crust ( $a_{0}=7 \mathrm{~km}, A=5 \quad 10^{-16}$ $\mathrm{s}^{-1}$ ) indicates that it retains its He during 395 myrs, and its $\mathrm{U}$ for 835 myrs. The corresponding thickness of the crustal layer when helium and uranium diffuses out, are $14 \mathrm{~m}$ and $1.4 \mathrm{~cm}$ respectively. The very large difference between the diffusion coefficients of these two elements ( 6 orders of magnitude) has only a moderate impact on their retention inside the advected anomalies (a factor 2 in the retention time). The mixing (stirring+diffusion) acts in a very different way from the slow usual diffusion: for times less than the homogeneisation time $t_{h}$ the elements are frozen in the flow after this time, they suddenly diffuse out exponentially.
Another important point that sometimes creates a misunderstanding between geochemists and geophysicists is the quantity of primitive material that may have remained unprocessed in the mantle. In convective flow, heterogeneities are constantly folded and stretched; as the size and the number of heterogeneities decreases, the probability of their being sampled under a ridge also decreases. The quantity of primitive material surviving convection therefore varies exponentially with time. Depending on the way the time dependence of Earth's mantle convection is parametrized, and assuming whole mantle convection, the remaining primitive material can account for $40 \%$ (even $60 \%$ in some extreme cases) to less than $3 \%$ of the mantle mass (van Keken and Ballentine, 1998; Ferrachat and Ricard, 2001; Davies, 2001). The fraction of undegassed mantle is very uncertain and depends on various assumptions regarding the history of mantle convection, the rheological properties of the mantle, the way the magma extraction is modeled and the presentday abundance of radiogenic heat sources. At least we know that a significant part of the mantle is still undegassed. The observation that $40 \%$ of the Ar produced is still in the mantle is not surprising in itself. However the primitive material should be mostly in the form of stripes, blobs, etc. of varying ages, partly erased by diffusion rather than taking the form of a homogeneous large scale reservoir. The primitive material should be intrinsically mixed with the recycled components and should also constitute a component of the shallow mantle.

\section{A whole mantle marble cake model}

Subduction of oceanic crust is one of the major observations leading to plate tectonic theory. The descending slabs can be tracked within the mantle using seismology or gravity. After several tens of myrs, they are thermally equilibrated with the surrounding mantle and almost undetectable by seismology. Slabs are then folded and elongated by convective mixing and dispersed everywhere in the mantle.

The concept of a marble-cake mantle, introduced by Allègre and Turcotte (1986) explains to first order the petrological and chemical heterogeneity of the shallow mantle. In this model, the shallow mantle is made of two components: peridotite and pyroxenite. The pyroxenite represents the oceanic crust stirred by convection embedded in a peridotite matrix. This is a well accepted view of the shallow mantle, supported by field observations and geochemistry of mantle rocks and MORBs. In peridotic massifs like BeniBoussera the pyroxenite layers have centimetric thicknesses which suggests that the $7 \mathrm{~km}$ thick oceanic crust has been stretched by a factor $10^{5}$. In the marble-cake mantle, the peridotite is itself a complex mixture. It contains the remaining primitive material that, as we have seen, is likely still to exist in the convective mantle. It also includes in large proportions, ancient depleted lithospheric mantle (from fertile and depleted lherzolite to residual harzburgite). It may also include the chemical elements of ancient crustal filaments 
below the centimeter scale that have been wiped out by diffusion.

We propose that this model for the shallow mantle can be extended to the whole mantle and can also explain the geochemistry of OIBs and the deep mantle structure. Four observations from geochemistry need to be reproduced: a reservoir with high incompatible element concentrations, the recycling of the subducted crust within OIB sources, the higher ${ }^{3} \mathrm{He} /{ }^{4} \mathrm{He}$ of some OIBs, and better mixing of MORB sources compared to OIB sources. At the same time, geophysics strongly argues for whole mantle convection.

The marble-cake model can explain the existence of a deep reservoir with high incompatible element content. The subducted oceanic crust transforms into eclogitic assemblages which are likely to be a few percent denser than the surrounding mantle except in a limited depth range below $670 \mathrm{~km}$ depth (Hirose et al., 1999). Numerical models incorporating mineralogical transformations combined with variable viscosity produce a layer of subducted crust at the base of the mantle, fed by slabs and entrained by plumes (Christensen and Hofmann, 1994; Tackley and Xie, 2002). This layer often displays an uneven thickness with interconnected ridges commonly known as a spoke pattern, with a total volume comparable to that of D". Hence, subduction of oceanic plates could have formed a deep reservoir, growing in time, rich in incompatible elements and poor in primitive volatiles that could account for the seismological complexities of D". We have seen in Figure 1 that such a layer can account for the balance of $U$ and Al. It can also account for the balance of other incompatible elements like rhenium (Hauri, 2002). This layer would explain why all plumes contain recycled slab components. The presence of piles of dense material at the base of the convective mantle could favor the relative fixity of hotspots (Davaille et al., 2002) and explain their low excess temperature (Farnetani, 1997).

The marble-cake model is also able to explain noble gas isotopes. As seen before, ${ }^{3} \mathrm{He}$ is the stable isotope. It escapes the mantle through melting and degassing. For this reason, only the peridotic component contains significant amounts of this isotope. The ${ }^{4} \mathrm{He}$ is produced from the decay of $\mathrm{U}$ and $\mathrm{Th}$, which are concentrated in the crust. Therefore the variability of ${ }^{3} \mathrm{He} /{ }^{4} \mathrm{He}$ ratios could be explained from the variability of the recycled crust fraction in the mantle sources of basalts.

A two component mantle where the mass fraction of recycled crust is $f$, has a helium composition such that

$$
\begin{aligned}
{\left[{ }^{3} \mathrm{He}\right]_{s} } & =(1-f)\left[{ }^{3} \mathrm{He}\right]_{p e r} \\
{\left[{ }^{4} \mathrm{He}\right]_{s} } & =f\left[{ }^{4} \mathrm{He}\right]_{c}+(1-f)\left[{ }^{4} \mathrm{He}\right]_{p e r}
\end{aligned}
$$

where $s, p e r$, and $c$ stand for source, peridotite and crust. These two equations are valid for the MORB source (or shallow mantle, SM) and we assume that such a source corresponds to a mass fraction of ancient crust, $f$, of $8 \%$ and helium concentrations of $12010^{-9} \mathrm{~mol} \mathrm{~g}^{-1}$ for ${ }^{4} \mathrm{He}$ and $1.410^{-12}$ for ${ }^{3} \mathrm{He}$ (i.e.a ${ }^{3} \mathrm{He} /{ }^{4} \mathrm{He}$ ratio of 8 times the at- mospheric ratio (Moreira et al., 1998)). We further assume that the ancient crust is 1.5 byrs old and contains $70 \mathrm{ppb} \mathrm{U}$, similar to modern MORBs. The observed U content of the shallow mantle, $7 \mathrm{ppb}$, would come partly from ancient crust contributing $5.6 \mathrm{ppb}(8 \% \times 70 \mathrm{ppb})$ and the rest from the peridotic component. All these estimates are subject to large uncertainties but the exact values do not affect our qualitative results.

We can now plot in Figure 2 the predicted ${ }^{3} \mathrm{He} /{ }^{4} \mathrm{He}$ ratio as a function of the fraction of oceanic crust in the OIB source, $f$. For simplicity we assume that the corresponding variability of $U$ in the same OIBs is only due to the variability in the source and that all hotspots far from ridges, have the same degree of partial melting, $1 \%$ ( $\mathrm{U}$ in the magma is $\sim 100$ times that in the source). This last approximation is certainly drastic but allows us to have a direct correspondence between the fraction of crust (top horizontal axis) and the $U$ content of the magma (bottom horizontal axis). It gives a very reasonable fit to the data taken from various hotspots. The shallow mantle source corresponds by hypothesis to a mass fraction of crust of $8 \%$ (top horizontal axis); with a melt fraction of $1 \%$ it would yield a basalt with $700 \mathrm{ppb} \mathrm{U}$ (bottom horizontal axis). A melt fraction of 10\%, appropriate to ridges, would produce a typical $70 \mathrm{ppb}$ U MORB. Figure 2 indicates that the highest ${ }^{3} \mathrm{He} /{ }^{4} \mathrm{He}$ ratio, corresponding to that found for Loihi could be obtained by mixing about $2 \%$ of ancient crust with peridotite whereas the lowest ratios such as that for Tristan would imply 35\% of crust in their source. This model implies that the ${ }^{3} \mathrm{He}$ concentrations in the sources of MORBs and OIBs are roughly the same as they vary with $1-f$ which is 0.98 for Loihi, 0.92 for MORBs, 0.65 for Tristan. Only the ${ }^{4} \mathrm{He}$ concentrations differ.

This simple two end-member model does not explain all the geochemical poles, but it accounts for other geochemical isotope observations that are also related to recycling (Coltice and Ricard, 2002). Components of the EM1, EM2 and HIMU poles indicate the need to take into account both continental and oceanic sediments. However, the presence of these minor ingredients in the source of plumes are not in conflict with the model outlined here. It seems to us, at any rate, that the primary difficulty in matching geochemical and geophysical views comes from the variability of noble gas ratios.

The fact that MORBs are better mixed than OIBs may come from two mechanisms. First, the melting zones of MORBs are sampling a much larger volume than those of OIBs, second, the shallow mantle is filled with material that is more thoroughly mixed than hotspots, which come from a heterogeneous stagnant bottom boundary layer. The process of crustal segregation maintains the presence of heterogeneities near the CMB.

As a conclusion, a two component marble cake mantle can account for the existence of a deep reservoir rich in incompatible elements and for the variability of noble gas concentration in mantle magmas. Moreover, this model is con- 
sistent with seismic observations of deep slab penetration and provides an origin for D" formed from the segregation of dense crust.

\section{Toward thermochemical convection}

The previous discussion in this paper shows that the only way to reconcile seismology and chemistry is explicitly to take account of petrology in geodynamic models. Clearly one of the major petrological density contrasts that exists in the mantle is that related to the difference in composition and mineralogy between the oceanic crust and the rest of the upper mantle.

A long standing model for upper mantle composition is

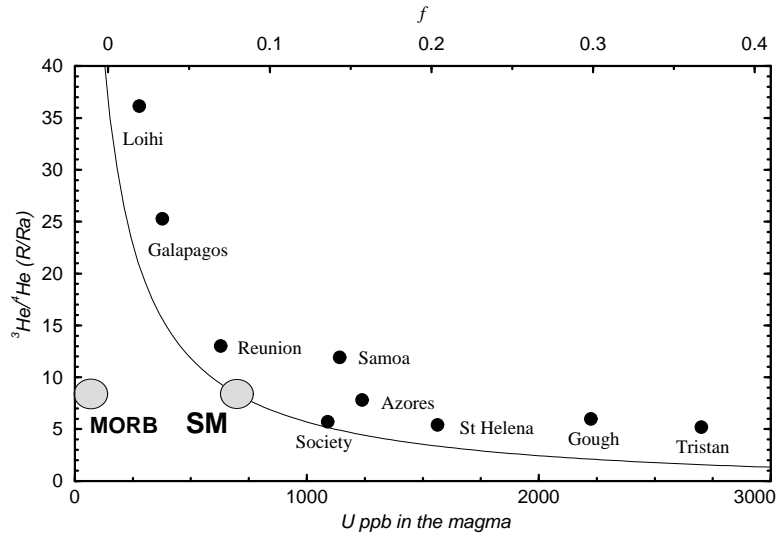
pyrolite. Pyrolite is therefore taken to be the average composition of the marble-cake mantle made of peridotite and pyroxenite. Its transformations at high pressure gives a good fit to PREM (see Figure 3). The oceanic crust is much richer in $\mathrm{Si}$ than pyrolite and has a much higher $\mathrm{Fe} / \mathrm{Mg}$ ratio. At depth, basalt transforms into a garnet/stishovite assemblage and at approximately $730 \mathrm{~km}$ depth, garnet transforms into perovskite/magnesiowüstite while the stishovite remains stable. Stishovite and Fe-rich assemblages are significantly denser than the olivine and the Fe-poor assemblages of the normal mantle. The high $\mathrm{Al}$ content slightly lightens the basalt. However, with the exception of depths between 650 and $730 \mathrm{~km}$ where the basalt remains as garnetite while the pyrolite has transformed into post spinel phases, the oceanic crust is a few percent denser (see Figure 3). The most depleted residue left after the extraction of the crust (harzburgite) is only very slightly lighter than pyrolite. From 730 to $\sim 900 \mathrm{~km}$ depth, there is a general agreement that eclogite is about 3\% denser than pyrolite (Hirose et al., 1999; Ono et al., 2001). In the deepest lower mantle the density evolution and even the structures of all the phases involved are not well known (Badro et al., 2003; Gillet et al., 2000). Figure 3 was computed using a rigorous selection of the equations of state of the various mineralogical phases (Matas, 1999). Even at CMB conditions, it is inferred that eclogite would be $\sim 1.5 \%$ denser. Other authors however suggest than the eclogite density may intersect the average mantle density in the lower mantle (Kesson et al., 1998; Ono et al., 2001).

The introduction of petrological components in thermal convection models is complex and the numerical simulations introduce a lot of approximations. A continuous representation of the concentrations is impossible since for affordable mesh sizes, artificial numerical diffusion would be much larger than any realistic chemical diffusion. The most common approach consists in using tracers advected by the flow and carrying chemical properties (Christensen and Hofmann, 1994; Ferrachat and Ricard, 2001; Tackley and Xie, 2002). The interpretation of the results of such models in term of petrology or geochemistry is not straightforward. The advection of tracers does not represent the real stretching of the material and diffusion cannot be taken into account. For statistical reasons a large number of tracers have 


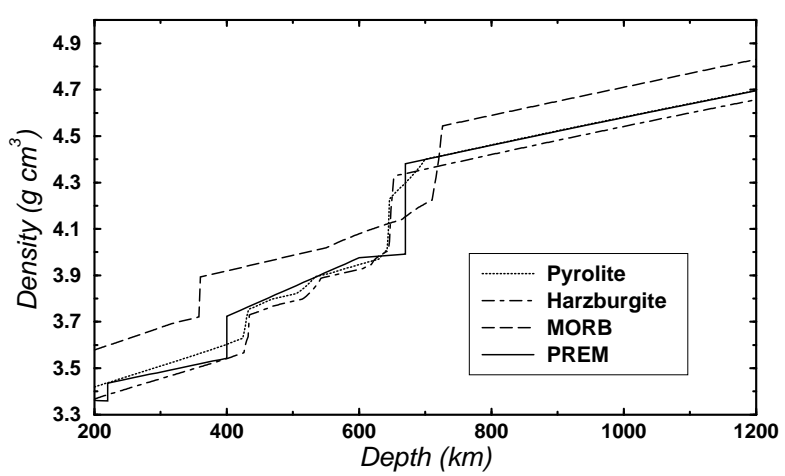

Figure 3. Densities of various petrological references as a function of depth, compared with the density in PREM. These densities have been computed from the thermodynamic properties of the various involved phases. The evolution of the phase diagrams have themselves been computed from Gibbs energy minimization (Matas, 1999). The pyrolite composition gives a rather close fit to PREM. The subducted crust always appears significantly denser than PREM except in a narrow zone on top of the lower mantle.

to be used even in 2D (typically one million) and 3D simulations are for now out of reach. Moreover, the differences between hotspots and ridges, i.e., between cylindrical and linear upwellings does not exist in 2D simulations. Another approach, consisting in the advection of the chemical interfaces is promising in 3D (Schmalzl and Loddoch, 2003). However to avoid the treatment of too convolved interfaces, topological simplifications are needed that introduce spurious diffusion.

In addition to numerical problems, modelers also have some conceptual problems. For all thermochemical numerical codes, there is the difficulty of handling the formation of the continental crust. This rate of formation controls the chemical and thermal budget of the Earth, but all these phenomena are largely ignored in convection models. The final difficulty arises from the need for a realistic self consistent representation of surface plate motion that organizes the mantle flow and is associated with stable subduction and more erratic ridges (Bercovici et al., 2000).

Various papers have presented and discussed 2D convection models with petrological components (Christensen and Hofmann, 1994; Samuel and Farnetani, 2002; Xie and Tackley, 2003). Some of the ingredients discussed above are indeed confirmed by these models. For example the remnants of primitive material in the mantle and the delamination of $\sim 20-30 \%$ of the eclogitized oceanic crust at the CMB (Christensen and Hofmann, 1994). This segregation occurs mostly in the hot boundary layer of the deep mantle, by Rayleigh-Taylor instability in the thickest parts of the oceanic crust. This favors the segregation of thick oceanic plateaus as also proposed from geochemical arguments (Albarède and van der Hilst, 2002). The segregation would also generate long lasting chemical heterogeneities near D", in the sluggish lower mantle. Some basaltic components may also be trapped just below the $670 \mathrm{~km}$ discontinuity (Mambole and Fleitout, 2002). Without this segregation, no differences in the sizes or compositions of heterogeneities are found between the upper and lower mantle (van Keken and Ballentine, 1998). This conclusion is not affected by a moderate viscosity increase with depth in the mantle, up to 2 or 3 orders of magnitude (Ferrachat and Ricard, 2001). However, due to the exclusive use of 2D simulations, it has remained difficult to predict precisely what should be sampled in active upwellings (hotspots) and passive ridges in these models.

Ten years ago geophysicists and geochemists were working with very different tools and concepts that appear now equally naive. While geophysicists were mostly thinking in terms of purely thermal convection, geochemists were mostly intepretating their observations in terms of isolated boxes. The basis for a common language has now been set up, where the petrological components play an important role and where the topology of the reservoirs has gained much complexity. On the other hand, a simple tool to study mantle chemical evolution is still unavailable until necessary ingredients like 3-dimensionality, a correct description of petrology, and continental crust evolution are introduced in thermochemical convection models.

\section{References}

Albarède, F., and R. D. van der Hilst, Zoned mantle convection, Phil. Trans. Royal Soc., 360, 2569-2592, 2002.

Allègre, C.J., and D.L. Turcotte, Implications of a two component marble-cake mantle, Nature, 323, 123-127, 1986.

Badro, J., G. Fiquet, F. Guyot, J.-P. Rueff, V.V. Struzhkin, and G. Vank, Iron partitioning in Earth's mantle: toward a deep lower-mantle discontinuity, Science, 300, 789-791, 2003.

Becker, T. W., J. B., Kellogg, and R.J. O’Connell, Thermal constraints on the survival of primitive blobs in the lower mantle, Earth Planet. Sci. Lett., 171, 351-365, 1999.

Bercovici, D., Y. Ricard, and M.A. Richards, The relation between mantle dynamics and plate tectonics: A primer, The History and Dynamics of Global Plate Motions, M.A. Richards, R. Gordon and R. Van der Hilst Ed., AGU Geophysical Monograph 21, 5-46, 2000.

Bijwaard, H., W. Spakman, and E.R. Engdahl, Closing the gap between regional and global travel time tomography, J. Geophys. Res., 103, 30055-30078, 1998.

Blichert-Toft, J., F.A. Frey, and F. Albarède, Hf isotope evidence for pelagic sediments in the source of Hawaiian basalts, Science, 285, 879-882, 1999.

Bunge, H.P., M.A. Richards, C. Lithgow-Bertelloni, J.R. Baumgardner, S.P. Grand, and B.A. Romanowicz, Time scales and heterogeneous structure in geodynamic Earth models, Science, 280, 91-95, 1998.

Castle, J.C., and R. D. van der Hilst, Searching for seismic scattering of mantle interfaces between 800 and $2000 \mathrm{~km}$ 
depth, J. Geophys. Res., 108, 2095-2109, 2003.

Chauvel, C., A.W. Hofmann, and P. Vidal, HIMU-EM: the French Polynesian connection, Earth Planet. Sci. Lett., 110, 99-119, 1992.

Christensen, U.R., The influence of trench migration on slab penetration into the lower mantle, Earth Planet. Sci. Lett., 140 , 27-39, 1996.

Christensen, U.R., and A.W. Hofmann, Segregation of subducted oceanic crust in the convecting mantle, J. Geophys. Res., 99, 19867-19884, 1994.

Coltice, N., and Y. Ricard, Geochemical observations and one layer mantle convection, Earth Planet. Sci. Lett., 174, 125-137, 1999.

Coltice, N., and Y. Ricard, On the origin of noble gases in mantle plumes, Phil. Trans. Royal Soc., 360, 2633-2648, 2002.

Davaille, A., F. Girard, and M. Le Bars, How to anchor hotspots in a convecting mantle?, Earth Planet. Sci. Lett., 203, 621-634, 2002.

Davies, G.F., Ocean bathymetry and mantle convection 1. large scale flow and hotspots, J. Geophys. Res., 93, 10467-10480, 1988.

Davies, G.F., Stirring geochemistry in mantle convection models with stiff plates and slabs, Geochim. Cosmochim. Acta, 66, 3125-3142, 2001.

du Vignaux, N.M., and L. Fleitout, Stretching and mixing of viscous blobs in Earth's mantle, J. Geophys. Res., 106, 30,893-30908, 2001

Eiler, J.M., K.A. Farley, J.M. Valley, A.W. Hofmann, and E.M. Stolper, Oxygen isotope constraints on the sources of Hawaiian volcanism, Earth Planet. Sci. Lett., 144, 453-468, 1996.

Farnetani, C.G., Excess temperature of mantle plumes: the role of chemical stratification across D", J. Geophys. Res., 24, 1583-1586, 1997.

Ferrachat, S., and, Y. Ricard, Regular vs. chaotic mantle mixing, Earth Planet. Sci. Lett., 155, 75-86, 1998.

Ferrachat, S. and Y. Ricard, Mixing properties in the Earth's mantle: Effects of the viscosity stratification and of oceanic crust segregation, Geochem. Geophys. Geosys., 2, 2000GC0000 2001.

Fukao, Y., S. Widiyantoro, and M. Obayashi, Stagnant slabs in the upper and lower mantle transition region, Rev. Geophys., 39, 291-323, 2001

Garnero, E.J., and D.V. Helmberger, A very slow basal layer underlying large-scale low-velocity anomalies in the lower mantle beneath the Pacific: evidence from core phases, Phys. Earth Planet. Inter., , 91, 161-176, 1995

Gillet, P., M. Chen, L. Dubrovinsky, and A. El Goresi, Natural $\mathrm{NaALSi}_{3} \mathrm{O}_{8}$-hollandite in the shocked Sixiangkou meteorite, Science, 287, 1633-1636, 2000.

Graham, D., J. Lupton, F. Albarède, and M. Condomines, Extreme temporal heterogeneity of helium isotopes at Piton de la Fournaise, Réunion island, Nature, 347, 545548, 1990.

Grand, S.P., R.D. van der Hilst, and S. Widiyantoro, Global seismic tomography: a snapshot of convection in the Earth, GSA Today, 7, 1-7, 1997.

Hanyu, T., and I. Kaneoka, The uniform and low ${ }^{3} \mathrm{He} /{ }^{4} \mathrm{He}$ ratios of HIMU basalts as evidence for their origin as recycled materials, Nature, 390, 273-276, 1997.

Hauri, E.H., Osmium isotopes and mantle convection, Phil. Trans. R. Soc. London A, 360, 2371-2382, 2002.

Hirose, K., Y. Fei, Y. Ma, and H.-K. Mao, The fate of subducted basaltic crust in the Earth's lower mantle, Nature, 397, 53-56, 1999.

Hofmann, A.W., Mantle geochemistry: the message from oceanic volcanism, Nature, 385, 219-229, 1997.

Hofmann, A.W., and S.R. Hart, An assessment of local and regional isotopic equilibrium in the mantle, Earth Planet. Sci. Lett., 38, 44-62, 1978.

Jochum, K.P., A.W. Hofmann, E. Ito, H.M. Seufert, and W.M. White, $\mathrm{K}, \mathrm{U}$ and $\mathrm{Th}$ in mid-ocean ridge basalt glasses and heat production, Nature, 306, 431-436, 1983.

Kellogg, L. H., and D. L. Turcotte, Homogeneisation of the mantle by convective mixing and diffusion, Earth Planet. Sci. Lett., 81, 371-378, 1987.

Kellogg, L.H., B.H. Hager, and R.D. van der Hilst, Compositional stratification in the deep mantle, Science, 283 , 1881-1884, 1999.

Kesson, S.E., J.D.F. Gerald, and J.M. Shelley, Mineralogy and dynamics of a pyrolite lower mantle, Nature, 393, 252-255, 1998.

Kurz, M.D., W.J. Jenkins, and S.R. Hart, Helium isotopic systematics of oceanic islands and mantle heterogeneity, Nature, 297, 43-47, 1982.

Mambole, A., and L. Fleitout, Petrological layering induced by an endothermic phase transition in the Earth's mantle, Geophys. Res. Lett., , 29, 2044-2047, 2002.

Matas, J., Modélisation thermochimique des proprétés de solides à hautes températures et hautes pressions. Applications géophysiques, $\mathrm{PhD}$, Ecole Normale de Lyon, 1999.

Montelli, R., G. Nolet, G. Masters, F.A. Dahlen, and S.-H. Hung, Global P and PP traveltime tomography: rays ver0098us waves, Geophys. J. Int., submitted, 2003.

Moreira, M., J. Kunz, and C.J. Allègre, Rare gas systematics in popping rock: isotopic and elemental compositions in the upper mantle, Science, 279, 1178-1181, 1998.

McDonough, W.F., and S. Sun, The composition of the Earth, Chem. Geol. 120, 223-253, 1995.

Nataf, H.-C., and J. C. VanDecar, Seismological detection of a mantle plume?, Nature, 264, 115-120, 1993.

Olson, P., D. A. Yuen, and D. Balsinger, Mixing of passive heterogeneities by mantle convection, J. Geophys. Res., 89, 425-436, 1984.

Ono, S, E. Ito, T., Katsura, Mineralogy of subducted basaltic crust (MORB) from 25 to $37 \mathrm{GPa}$, and chemical heterogeneity of the lower mantle, Earth Planet. Sci. Lett., 190, 57-63, 2001.

Ottino, J. M., The Kinematics of Mixing: Stretching, Chaos, and Transport, Cambridge Univ. Press, New York, 1989. 
Ricard, Y., M.A. Richards, C. Lithgow-Bertelloni, and Y. LeStunff, A geodynamic model of mantle density heterogeneity, J. Geophys. Res., 98, 21895-21909, 1993.

Richards, M.A., R.A. Duncan and V.E. Courtillot, Flood basalts and hot-spot tracks: plume heads and tails, Science, 246, 103-107, 1989.

Saltzer, R., R.D. Van der Hilst, and H. Karason, Comparing $\mathrm{P}$ and $\mathrm{S}$ wave heterogeneity in the mantle, Geophys. Res. Lett., , 28, 1335-1338, 2001.

Schmalzl, J., and A. Loddoch, Using subdivision surfaces and adaptative surface simplification algorithms for modeling chemical heterogeneities in geophysical flows, Geochem. Geophys. Geosys., 4, 8303, doi:10.1029/2003GC000578, 2003.

Sims, K.W., and D.J. DePaolo, Inferences about mantle magma sources from incompatible element concentration ratios in oceanic basalts, Geochim. Cosmochim. Acta, 61, 765-784, 1997.

Sleep, N.H., Hotspots and plumes: some phenomenology, $J$. Geophys. Res., 95, 6715-6736, 1990.

Steinberger, B., and R.J. O'Connell, Advection of plumes in mantle flow; implications on hotspot motion, mantle viscosity and plume distribution, Geophys. J. Int., 132, 412-434, 1998.

Tackley, P.J., and S.X. Xie, The thermochemical structure and evolution of Earth's mantle: constraints and numerical models, Philos. Trans. Roy. Astron. Soc., 1800, 2593-2609, 2002.

Trull, T.W., and M.D. Kurz, Experimental measurements of He-3 and He-4 mobility in olivine and clinopyroxene at magmatic temperatures, Geochim Cosmochim. Acta, 57, 1313-1324, 1993.

Tyburczy, J.A., B. Frisch, and T.J. Arhens, Shock-induced volatile loss from a carbonaceous chondrite: implications for planetary accretion, Earth Planet. Sci. Lett., 80, 201207, 1986.

van der Voo R., W. Spakman, and H. Bijwaard, Tethyan subducted slabs under India, Earth Planet. Sci. Lett., 171, 7-20, 1999.

van Keken, P.E., and C.J. Ballentine, Whole-mantle versus layered convection and the role of a high-viscosity lower mantle in terrestrial volatile evolution, Earth Planet. Sci. Lett., 156, 19-32, 1998.

Vinnik, L., B. Romanowicz, Y. LeStunff, and L. Makeyeva, Seismic anisotropy in the D" layer, Geophys. Res. Lett., , 22, 1657-1660, 1995.

Weber, M., J.P. Davis, C. Thomas, F. Krger, F. Scherbaum, J. Schlittenhardt, and M. Krnig, The structure of the lowermost mantle as determined from using seismic arrays; In: Seismic modeling of the Earth's structure, Eds. Boschi, E., Ekstrm, G., Morelli A., Istituto Nazionale di Geophysica, Roma, 399-442, 1996.

Zindler, A., and S. Hart, Chemical geodynamics, Annu. Rev. Earth Planet. Sci., 14, 493-571, 1986.

Y. Ricard, Laboratoire des Sciences de la Terre, Ecole Normale Supérieure de Lyon, 46 allée d'Italie, F-69364
Lyon, Cedex 07, France. (ricard@ens-lyon.fr)

N. Coltice, Laboratoire des Sciences de la Terre, Ecole Normale Supérieure de Lyon, 46 allée d'Italie, F-69364 Lyon, Cedex 07, France. (ricard@ens-lyon.fr)

This preprint was prepared with AGU's LTTE $_{\mathrm{E}} \mathrm{X}$ macros v4, with the extension package 'AGU ${ }^{++}$' by P. W. Daly, version 1.6b from 1999/08/19. 